Mariano, C.S. ', Sá, L.R.M ${ }^{2}$ Málaga, S.K.' musculatura lisa, ele pode ser preconizado. A melhora observada neste caso apenas com tratamento sintomático poderia indicar que a causa seria secundária a esofagite de refluxo, porém, como há relatos de remissão espontânea tanto no megaesôfago congênito como no idiopático elas não puderam ser descartadas. Embora raro, o megaesôfago em felinos tem um prognóstico melhor do que em cães, uma vez que a grande maioria dos animais tratados apresentam melhora clínica.

\section{1 - Displasia microvascular hepática. Relato de um caso}

1- Médica Veterinária Autônoma

2- Departamento de Patologia da Faculdade de Medicina Veterinária e Zootecnia da Universidade de São Paulo, São Paulo-SP

Displasia microvascular hepática (DMH) é uma doença que se caracteriza por alterações microscópicas da vascularização hepática de cães e gatos. Geralmente, esta entidade está associada a desvio porto-sistêmico macroscópico. E uma desordem vascular congênita, incurável e pouco relatada na literatura. Este trabalho relata ocorrência de DMH em um cào, caracterizando suas alterações clínicas, laboratoriais e histopatológicas. Um cão da raça Poodle toy, macho, 1 ano e 4 meses, foi examinado clinicamente por apresentar hiporexia, apatia e aumento de volume abdominal há 5 dias. Amostras de urina e sangue foram colhidas para urinálise, hemograma e perfil bioquímico. Foram realizados ultra-sonografia de abdômen e biópsia hepática em cunha. Os fragmentos de fígado foram processados segundo técnica padrào para exame histopatológico e corados por hematoxilina e eosina, Tricrômico de Massom, Azul de Perls e coloração para fibras reticulares. Ao exame clínico foi constatado ascite e o líquido se caracterizou por ser amarelo citrino e com aspecto límpido. $\mathrm{O}$ exame de urina revelou densidade urinária de 1,$030 ; \mathrm{pH} 5,0$; presença de hemoglobina/eritrócitos +- e cristais de oxalato de cálcio + - O hemograma, bem como os valores bioquímicos de glicose, uréia e creatinina estavam dentro dos valores de referência. Na primeira avaliação da função hepática obteve-se os seguintes resultados: proteínas totais de $3.4 \mathrm{~g} / \mathrm{dl}$, albumina $1.7 \mathrm{~g} / \mathrm{dl}$, globulina $1.7 \mathrm{~g} / \mathrm{dl}$ e ALT $203 \mathrm{U} / \mathrm{l}$. Na segunda, proteínas totais $3.6 \mathrm{~g} / \mathrm{dl}$, albumina $1.6 \mathrm{~g} / \mathrm{dl}$, globulina $2.0 \mathrm{~g} / \mathrm{dl}$ e ALT 253U $/ \mathrm{le}$ AST $110 \mathrm{U} / \mathrm{L}$. A ultra-sonografia do abdômen mostrou figado de dimensões reduzidas, contornos regulares, ecogenicidade elevada, ecotextura grosseira, e presença de grande quantidade de líquido abdominal livre. Macroscopicamente, os fragmentos de figado apresentavam contornos irregulares, consistência fibrosa e aspecto lobulado tanto na superficie externa, como na de corte. Microscopicamente, observou-se ausência da veia porta em alguns espaços-portas, dilatação de veia porta, vasos anômalos intralobulares, espessamento de vênulas hepáticas terminais associado ou não a discreto infiltrado linfocítico, diminuição do lóbulo hepático e proximidade entre espaços porta e vênula hepática terminal. Com a coloração de Tricrômico de Masson, evidenciou-se fibrose mural de vênulas hepáticas, algumas com diminuição do lúmen e discreta fibrose portal. Presença de células de Kupffer com pigmentos de hemossiderina, corados pelo azul de Perls, tanto nos espaços periportais, como distribuídas multifocalmente. Ausência de processo necro-inflamatório ou neoplásico hepático no material examinado. As alterações microscópicas observadas são similares as descritas na literatura nos casos de $\mathrm{DMH}$ e, em alguns casos de desvio porto-sistêmico. As alteraçòes clínicas de ambas entidades são similares, contudo os càes somente com $\mathrm{DMH}$, geralmente, apresentam sinais clínicos menos severos e melhor prognóstico a longo prazo. A não observação de encefalopatia hepática sugere ausência de desvio porto-sistêmico macroscópico ou um desvio de menor intensidade. Por outro lado, o diagnóstico definitivo de desvio porto-sistêmico necessita de exames complementares como sintigrafia coloretal, portografia e dosagem pré e pós prandial de ácidos biliares séricos, que não foram realizados por não serem exames utilizados na rotina médico veterinária do nosso meio. A abordagem por laparotomia exploratória, para 
confirmação do desvio, não foi autorizada pelos proprietários. Assim, as alterações clínicas, laboratoriais, ultra-sonográficas e histopatológicas permitem o diagnóstico de DMH, mas não excluem a possível associação com desvio porto-sistêmico macroscópico.

\section{2 - Estenose esofágica por Tricobezoar gástrico no cão. Relato de caso}

Yoshitoshi, F. N.'; Migliani,M.2; Taboada, P. ${ }^{3}$

\author{
1- Serviço de Endoscopia Veterinária \\ 2- Clinica Veterinária Faria Lima, São Paulo-SP \\ 3- Serviço de Anatomia Patológica
}

As estenoses esofágicas são bandas de tecido fibroso intraluminal ou intramural que levam a obstrução total ou parcial do esôfago, podendo ser conseqüente a lesões por corpos estranhos, esofagites, ulceras, agentes cáusticos ou pelo refluxo e estase de suco gástrico na mucosa esofágica nos animais submetidos a anestesia geral. As estenoses mais comuns são aquelas ocasionadas pela lesão tecidual secundária ao corpo estranho em esôfago e são observados sinais de regurgitação a dietas sólidas e em caso de obstrução parcial, uma parte do bolo alimentar pode progredir para o estomago. Não há predileção sexual e não são relacionados a idade $\mathrm{e}$ ao porte, podendo ocorrer tanto em cão quanto em gato. Foi atendido na clínica veterinária, um cão pincher , 4 anos, fêmea, com histórico de regurgitação há 4 meses. Ao exame clínico foi observado caquexia, mucosas perláceas e fraqueza muscular. Ao esofagograma, não houve progressão do contraste em terço posterior esofágico evidenciando dilatação em região anterior. Pela endoscopia foi confirmada a estenose esofágica em regiào próxima a cárdia, não permitindo progressão do tubo endoscópico para a cavidade gástrica. O proprietário ciente do prognóstico e custo do tratamento, optou pela eutanásia. Na necrópsia foi confirmado a dilatação esofágica, estenose em cárdia e encontrado na cavidade gástrica várias erosões em mucosa e também um tricobezoar. $\mathrm{A}$ presença do tricobezoar em cavidade gástrica, provavelmente deve ter levado o cão a mímica de vômito, causando um aumento de refluxo de suco gástrico na mucosa esofágica levando a um processo de esofagite e conseqüente estenose.

\section{3 - Reinfecção de cães por Babesia Canis: aspectos clínicos, hematológicos e imunidade humoral}

1- Pós-graduando do Departamento de Clínica Médica da Faculdade de Medicina Veterinária e Zootecnia da Universidade de São Paulo, São Paulo-SP

2- Professora Titular do Departamento de Clínica Médica da Faculdade de Medicina Veterinária e Zootecnia da Universidade de São Paulo, São Paulo-SP

A infecção por B. canis, hematozoário transmitido aos cães pelo carrapato Rhipicephallus sanguineus caracteriza-se, principalmente, pelo desenvolvimento de anemia hemolitica, de características regenerativas, esplenomegalia, trombocitopenia e febre intermitente. A icterícia pode ou não se desenvolver conseqüente à destruição intra ou extra vascular dos eritrócitos parasitados. A gravidade dos sintomas varia com a cepa de B. canis envolvida, idade e estado imune do hospedeiro. A infecção por Babesia sp, principalmente as cepas mais virulentas, resulta no estado de "pré-imunição" ou imunidade de presença, em que a infecção residual propicia ao hospedeiro imunidade contra as infecções subsequentes. Com o objetivo de avaliar a resistência dos cães à reinfecção, dez cães que haviam sido infectados com cepa local de B. canis, das quais a última infecção havia ocorrido há doze meses, receberam $5 \mathrm{~mL}$ de sangue parasitado por B. canis (cepa homóloga) por via I.V.. Temperatura corpórea, parasitemia, esplenomegalia, eritrograma, plaquetometria e título de anticorpos (IF) foram 